\title{
Deus e o Diabo na Fronteira com os gentios
}

MOACYR FLORES*

Resumo: Esta reflexão sobre a fronteira cultural entre índios e brancos, nos séculos XVI e XVII, é baseada nos mitos indígenas, nas cartas e ânuas dos missionários e nos compêndios de teologia moral. Os cristãos criaram uma sociedade, como um espaço cristão, onde o índio deveria ser incorporado. Os que ficavam no espaço exterior pertenciam às hostes do Demônio e deveriam ser convertidos ou eliminados.

Abstract: This reflection on the cultural border among Indians and White, in the $16^{\text {th }}$ and $17^{\text {th }}$ centuries, is based on the indigenous myths, on the letters and the missionaries' anuas and on the summaries of moral theology. The Christians created a society, as a Christian space, where the Indians should be incorporate. The ones that remaind on the external space belonged to the demon's hostess and they should be converted or eliminated.

Palavras-chave: Fronteira. Cultura. Moral. Pecado.

Key words: Border. Culture. Moral. Sin.

Os índios consideravam sagrado o espaço que habitavam. $\mathrm{O}$ mundo natural e sobrenatural estavam interligados. Através do ritual podiam passar de um mundo para outro. Inclusive os sonhos eram considerados como proféticos. $\mathrm{O}$ ato de cortar uma árvore, o início de uma caçada ou a partida para uma guerra estavam marcados pelos rituais. Nada se fazia sem consultar o pajé, que conhecia as rezas, a maneiras de expulsar os espíritos dos mortos, de proteger os caçadores e que mantinha as tradição do grupo.

* Professor Doutor em História do Programa de Pós-Graduação em História da Pontifícia Universidade Católica do Rio Grande do Sul, Porto Alegre, Brasil. 
O território habitado, o teko-hã, estava organizado com roças, locais de caça, aldeia, trilhas e cemitério. Fora do teko-hã, além de sua fronteira marcada nas árvores e nas pedras, ficava o território do inimigo, um outro espaço caótico povoado por monstros, demônios e espíritos dos mortos. O índio banido de sua aldeia é tomado pela angústia e só lhe resta esperar a morte.

O mundo do índio é um mundo criado que pode ser destruído como já fora inúmeras vezes pelo fogo, pelo dilúvio ou por monstros. Mas sempre poderá ser reconstruído, desde que seja mantida a tradição e o contato com o mundo sobrenatural, reproduzido na disposição das casas da aldeia, nas trilhas e nos campos de caça, conforme seus mitos.

Se esse mundo não presta, o índio se suicida, como os kaiowás atualmente no Mato Grosso (que estão tendo seu mundo destruído por pastores pentecostais), para renascerem num mundo melhor, ou então migrarem em busca do Ivy Maray, a terra sem males, o paraíso na terra, onde há caça abundante, água e calor.

Essa cosmovisão indígena facilitou a conquista dos espanhóis e dos portugueses. Os guaranis, do lado espanhol, e os tupis com os portugueses, acreditavam que as reduções jesuíticas e franciscanas eram o Ivy Maray e que os conquistadores estavam construindo um novo mundo, não com Monan o deus criador, mas com Tupã, o deus do raio, do trovão e da destruição. Aquele que veio destruir a cultura indígena.

Os conquistadores portugueses tomaram posse da terra em nome de Cristo. O primeiro ato simbólico foi a ereção da cruz e logo após a missa. A terra descoberta recebeu o nome de Santa Cruz, depois o nome de Brasil.

A ocupação inicial foi caótica. Os portugueses ficaram na feitoria e mantiveram o escambo com os índios. Os brancos não eram gente, usavam barba, roupas e falavam outra língua. Muitas vezes tornaram-se inimigos, foram capturados e devorados num ritual antropofágico, que unia em comunhão os membros dos diferentes clãs. Outras vezes, os índios entregaram suas mulheres, uniam-se ao branco para lutar contra seus inimigos.

A grande mudança do espaço sagrado e profano ocorreu quando os colonizadores trouxeram missionários para formar uma nova sociedade com os valores da cristandade. A Igreja estava na fase do catolicismo guerreiro e considerava a evangelização igual a uma cruzada contra os infiéis, tanto que os índios eram considerados como gentios. Assim, o índio se salvaria ao ser convertido à fé católica, a única considerada verdadeira. $O$ índio cris- 
tão era inserido na sociedade luso-brasileira, originando uma população mestiça pela união do branco com a índia.

Surgiu a fronteira de Deus e do diabo. O projeto evangelizador era conflitante, porque não aceitava o índio não colonizado, chamado de infiel ou gentio.

Quando os padres José de Anchieta e Manoel da Nóbrega afirmavam que os índios não tinham religião e nem ídolos, queriam dizer que os indígenas não conheciam o cristianismo, pois em várias cartas descrevem rituais com cânticos, danças e usos de chocalhos em forma de cabaças.

Os missionários concebiam um espaço ideológico onde só deveria existir a cristandade. Quaisquer outros conceitos eram considerados heresia ou então um vazio que significava a ausência de Deus. Se Deus não estivesse presente, então o Diabo ocupava esse lugar. O espaço pagão da América deveria ser preenchido pela catequese, oração e trabalho.

No imaginário religioso havia a fantasia guerreira de conquista do espaço dominado por Satã para a instalação gloriosa do Reino de Deus, que não era deste mundo mas estava dentro de cada um. Os missionários preocupavam-se mais em salvar a alma, batizando, confessando e perdoando os pecados, do que salvar o corpo. No imaginário cristão, a dor purificava a alma e preparava o cristão para uma vida melhor. Aquele que mais sofresse neste mundo teria maior recompensa no outro mundo. Nesse sentido, a ordem terceira franciscana congregou os brasileiros em torno da caridade, da penitência e da oração do rosário.

O espaço cristão era marcado simbolicamente pela igreja ou pela capela, pelos muros da cidade, pelo pelourinho, pelas cruzes do campo santo, pelos nomes de santos dados aos lugares. Era um espaço ordenado pela religião e pela lei. Desde a Idade Média o templo era a imagem santificada do cosmos. Apesar do templo santificar o mundo, o Demônio podia entrar pelos becos escuros, pelas tavernas ou ser trazido pelas mulheres desonestas.

A conversão compreendia o abandono dos antigos valores, considerados como coisas do diabo, e a adoção de elementos culturais da cristandade. Civilizar significava tirar os índios da barbárie, colocando-os numa redução em forma de aldeia ou de povoado, transformando-os em colonos e milicianos como súditos da Coroa portuguesa.

Civilizar era colocar o ameríndio na civitas como se fosse a cidade de Deus. A redução era o espaço mágico onde reinava a luz, o bem, os santos, os anjos, Nossa Senhora e Cristo, Salvador dos homens. Na redução havia calor, comida e proteção. Lá fora 
ficava a incerteza da caçada, da pescaria e a falta de proteção contra a cobiça dos encomenderos espanhóis e dos escravocratas portugueses. Lá fora ficava a terrível selva e quem nela habitasse era considerado selvagem e adepto do demônio.

Civilizar tinha também o sentido de proteger os índios da escravidão, tanto dos espanhóis como dos portugueses, pois a legislação proibia a servidão de indígenas cristãos. Só o gentio aprisionado em guerra justa podia ser escravizado. Civilizar era romper com as tradições que mantinham as estruturas tribais, para inserir o índio na cristandade.

A catequese tornou-se um instrumento de dominação para as Coroas espanhola e portuguesa, pois não buscava a hegemonia dos povos nativos, mas sim a confirmação de um novo território de um rei cristão, onde a América espanhola e portuguesa constituíram-se em estado missional, com as reduções desenvolvendo uma experiência mística numa nova comunidade religiosa indígena, como veremos a seguir.

Inicialmente as novas terras descobertas por Portugal e Espanha estiveram marcadas pelas bulas pontifícias, pois no século XVI a Santa Fé era considerada pelos povos cristãos como o único tribunal da paz internacional. Tanto a política internacional como a nacional passaram a preocupar-se em reduzir os infiéis à fé católica no ato de conquistar novas terras.

As bulas Inter coetera, Eximia devotionis, Dudum siquidem, de maio e setembro de 1493, e a Universalis Ecclesiae, de 28 de julho de 1508 , concederam aos reis de Castela e de Portugal o régio padroado, que regia os limites da evangelização e da encomienda, o direito de indicar os bispos e autoridades eclesiásticas, o dever de financiar a cristianização. A quarta bula outorgou o direito das Coroas de recolherem o dízimo e de administrarem os bens religiosos (Morales Padrón, p. 420-421).

As Ordenações do Reino, de Filipe II, título III, reúnem a legislação específica sobre as reduções e povoados indígenas. Essa legislação deixa bem claro que a redução é uma reorganização espacial onde os índios eram instruídos na Santa Fé Católica e nas Leis Evangélicas, a serviço de Deus e do rei. Os ritos, cerimônias e erros do antigo espaço indígena deveriam ser esquecidos.

No Novo Mundo a fronteira entre o espaço cristão e o dos gentios foi mais marcante do que a imprecisa linha de Tordesilhas. O espaço cristão era dos seguidores de Cristo, civilizado pelas vilas e cidades, organizado pelos cabildos e câmaras municipais, regrado pelas Ordenações do Reino, marcado pelo pecado, pela confissão, pela penitência e pelo perdão. O medo do Santo Ofício 
regulava as relações entre os colonos, tolhia as criações literárias, inibia os instintos e controlava as heresias. Nos regulamentos do Santo Ofício português a maior falta era a inconfidência ao rei, vigário de Cristo, punida com morte natural na forca, esquartejamento e maldição até a terceira geração.

O espaço dos gentios era o reino do demônio, do pecado, dos vícios, da desorganização, do canibalismo, dos feiticeiros e do pecado gerado pela sensualidade desenfreada das índias. Era o espaço dos selvagens, dos bárbaros, onde dominavam os demônios que deveriam ser esmagados como a Virgem esmagou a cabeça da serpente. No imaginário indígena, as forças do mal não faziam o ser humano pecar, podiam quanto muito trazer doença, loucura ou fazer o índio perder a caça ou o caminho da aldeia. "Não havia pecado abaixo da linha do Equador", conforme afirmou frei Vicente Salvador no início do século XVII.

No imaginário dos missionários, os índios que se negavam a atravessar a fronteira entre a barbárie e a civilização da cristandade, eram manipulados pelo demônio, conforme concepção maniqueísta da época. Tudo que dava certo e era bom, era considerado como obra de Deus. Tudo que não dava certo ou não prestava, era obra do demônio.

O beato José de Anchieta, em seu poema Dos feitos de Mem de Sá, louvou a matança de índios infiéis porque assim diminuíam os soldados dos demônios. Em sua peça teatral Auto da Festa de São Lourenço, os demônios falam em tupi, enquanto os anjos e santos falam em português. No discurso do colonizador estabeleceu-se a raia entre cristãos e infiéis, entre Deus e o demônio, entre os civilizados e os selvagens. Tudo que é bom e santo vinha de Portugal, tudo que é mau e demoníaco vinha dos índios tupis.

Em carta de Piratininga, Anchieta escreveu que todos os missionários pediam e desejavam que a terra fosse povoada por cristãos e que a tivessem sujeita, porque os índios eram indômitos e comiam carne humana. Se fossem descobertos metais, a terra facilmente seria povoada e os índios, que eram tiranizados pelo demônio, se converteriam ao Criador (Anchieta, 1988, p. 87).

O padre Montoya, em sua obra Conquista espiritual, traçou o objetivo da catequese dos índios na Província do Paraguai, que também é válido para os índios do Brasil:

"fazer dos gentios filhos de Deus, libertando-os da escravidão do Demônio” (Montoya, 1985, p. 22).

A preocupação de Anchieta era de que os índios abandonassem os costumes antigos, chamando-os para a vida eterna. A cate- 
quese era feita com muito cuidado e só se dava o batismo depois de uma longa prova, para que não retornassem ao erro dos antigos costumes da antropofagia, poligamia e bebedeira (Anchieta, 1988, p. 49).

Essa idéia era comum aos missionários, que não se preocuparam em apreender a cultura indígena, considerando-a como artimanha do demônio, vivendo num espaço vazio onde reinava o maligno. Dentro desta concepção, José de Anchieta, na Gesta de Mem de Sá, tece louvores ao herói português que matou tantos índios infiéis, diminuindo as hostes do diabo.

A dualidade do barroco aceitava a luta entre o bem e o mal, podendo este vencer temporariamente, mas no final o bem sairia sempre vitorioso. O padre Antônio Sepp, depois de distribuir os lotes entre os índios, mandou levantar uma cruz para limite de seus campos, e antes de ararem a terra, ele lançou a

"bênção dos campos para expulsar os demônios que, por causa da infidelidade destes gentios, habitavam despreocupados estes lugares tanto tempo e tantos séculos" (Sepp, 1971, p. 146).

O padre Simão de Vasconcelos (1597-1671), ao descrever os costumes indígenas, afirma:

"Os tapuias neste particular são os piores, porque, além de não conhecerem Deus, crêem invisivelmente no Diabo em formas ridículas de mosquitos, sapos, ratos e outros animais desprezíveis. Os feiticeiros agoureiros e curadores são entre eles os mais estimados; a estes dão toda a veneração e que dizem para com eles é infalível" (Vasconcelos, 1977, p. 121).

Os pajés tinham ascendência sobre os ameríndios, pois praticavam exorcismo sobre os espíritos, controlavam as forças naturais, aliviavam as doenças e traziam a morte. Guardiões da tradição, os feiticeiros transmitiam os mitos e crenças que davam coesão ao grupo tribal, explicando as causas desconhecidas dos fenômenos naturais e educando a juventude. Os inacianos, recebidos pelos índios como poderosos feiticeiros (pajé-guaçu) porque curavam, rezavam e falavam de Deus, trataram os pajés como seguidores do espírito do mal, proibindo magias e rituais indígenas.

Pecado da luxúria era cometido pelos colonizadores porque não resistiam à tentação das índias, negras e mulatas. A mulher indígena tinha o gosto pelo pecado da luxúria, pois sua sensualidade não era reprimida. A mulher negra segue uma religião mágica e feminina, onde o sexo não é pecado. 
Em suas cartas, o padre Manoel da Nóbrega informava que no Brasil há grande soma de homens casados em Portugal que vivem em grande pecado, com várias mulheres índias, tendo com elas filhos. O governador Duarte Coelho e sua esposa D. Brites de Albuquerque apoiavam os missionários em sua luta contra o pecado, que pregavam duas vezes nos domingos e todas as sextasfeiras praticavam a disciplina com muito proveito para todos, que iam se confessando e fazendo penitência, tanto os brancos como os índios (Nóbrega, 1988, p. 120-121).

Os portugueses viviam amancebados e os gentios não consideravam pecado trocar de mulheres e nem o adultério era considerado falta grave. Escandalizado, o padre Nóbrega em carta de 1551 solicita que ao rei que

"Mande mulheres órfãs para as outras capitanias, que todas casarão. Nesta (Pernambuco) não são necessárias por haverem muitas filhas de homens brancos e de índias da terra, as quais todas agora casarão com a ajuda do Senhor, e si não casavam antes era porque consentiam viver os homens em seus pecados livremente e por isso não se curavam tanto de casar, e alguns diziam que não pecavam, porque o arcebispo do Funchal lhes dava licença" (Nóbrega, 1988, p. 126).

Em outra carta de 1552, o padre Nóbrega pediu ao rei que mandasse mulheres brancas para que os homens pudessem viver apartados do pecado:

"Mande Vossa Alteza muitas órfãs e si hão houver muitas, venham de mistura delas e quaisquer, porque são tão desejadas as mulheres brancas cá, que quaisquer farão cá muito bem à terra, e elas se ganharão e os homens de cá apartar-se-ão do pecado" (Nóbrega, 1988, p. 133).

O Demônio estava presente no imaginário europeu até o século XVII. No arquétipo judaico-cristão a mulher era considerada como instrumento do Demônio, por ser inferior ao homem, ainda mais que sabia agir com malícia. Toda a bruxaria tinha origem na cobiça carnal, insaciável nas mulheres ambiciosas e vaidosas, que chegavam a copular com o próprio tinhoso (Kramer, 1991, p. 119122).

O piedoso padre Antônio Sepp ao encontrar pela primeira vez uma mulher iaró, comparou-a com uma bruxa infernal, verdadeira megera, sanguinária tigresa de rosto feio, colo e peitos desnudos, achando improvável que haja uma mulher bela entre estas fúrias infernais (Sepp, 1971, p. 174). 
Os colonizadores reorganizaram o espaço indígena com elementos e valores da cristandade, ignorando os costumes indígenas. O oferecimento de mulheres do grupo, por parte do índio, foi um costume mal interpretado pelo europeu. A mulher tinha liberdade sexual, mas os parentes controlavam as mulheres para depois pedirem indenização a seus parceiros. Quando ofereciam uma índia ao branco, tinham direito a uma indenização e também a mulher se transformava num penhor de aliança.

Dentro dos valores morais da cristandade, a luxúria era o maior dos sete pecados capitais, porque levava o pecador aos demais pecados. A sexualidade da mulher indígena surpreendeu o espanhol e o português, escandalizou os missionários e chamou a atenção dos viajantes europeus. O padre Sepp afirmou diversas vezes em suas obras que os índios não pecavam a não ser contra o sexto mandamento, que aumentava a fila do confessionário.

Os padres José de Anchieta e Manoel da Nóbrega já repararam que os brancos viviam com todos os hediondos vícios, inclusive o clero, com padres tendo mulheres. Anchieta conta que para manter uma moça pura, isto é, casta, realizou uma coleta para lhe dar um dote e assim casá-la. O casamento era um meio para evitar o grave pecado contra a castidade e para terminar com a licenciosidade entre a índia e o branco (Anchieta, 1989, p. 61-66).

O padre Simão de Vasconcelos ao descrever os índios do litoral do Brasil afirmou que neles a luz da razão era apagada, quase iguais a feras, pareciam mais brutos em pé, que racionais humanados, eram uns semicapros, uns faunos, uns sátiros dos antigos poetas. Os índios não tinham amor às suas mulheres, largando-as por qualquer desgosto com a mesma facilidade que as recebiam. $\mathrm{O}$ pior era que o poder do inferno havia se assenhoreado por seis mil e tantos anos do vasto império da gentilidade brasílica, restando agora aos missionários a conquista dessas almas. O padre Vasconcelos lembrou ainda que o Demônio é o pai da sensualidade, contando histórias de mulheres amancebadas até com padres, ou vivendo dentro de casa com o Demônio como se fossem marido e mulher, em terras de Portugal (Vasconcelos, 1977, p. 49, 97, 103, 176 e 177).

O padre Ruiz de Montoya narrou que pregava nos sermões dominicais os mistérios da fé e os preceitos divinos. Quanto ao sexto mandamento guardou silêncio por dois anos em público, evitando que os neófitos tomassem ódio pelo Evangelho. Durante esse período o Demônio tentou constantemente os missionários, fazendo com que os caciques oferecessem mulheres aos padres. Para afastar as tentações, Montoya cercou sua residência com ma- 
deiras para impedir a entrada de mulheres, o que causou estranheza aos índios, por considerarem a abstinência sexual contrária à natureza humana (Montoya, 1985, p. 56-57).

Por que os missionários referem-se mais à sensualidade da mulher e não do homem indígena, alguns possuindo várias mulheres? Porque na construção dos arquétipos cristãos a mulher era considerada inferior ao homem, inferioridade expressa na vida institucional da própria Igreja e na herança do Talmude. Os inquisidores alemães Heinrich Kramer e James Sprenger, em 1484, consideravam a mulher como sendo criada de uma costela torta de Adão, portanto incapaz de agir retamente, sabendo apenas usar de malícia em suas ações. As presas mais fáceis do Demônio eram as mulheres vaidosas e ambiciosas, que até pela voz faziam os homens pecarem. Assim sendo, as mulheres eram mais criminosas e pecadoras que os homens. Afirmavam que o primeiro pecado que tornou o homem escravo do Demônio foi o do ato carnal. Toda a bruxaria

"tem origem na cobiça carnal, insaciável nas mulheres, para saciarem a sua lascívia copulam até mesmo com demônios" (Kramer, 1991, p. 119-122).

A cristandade cresceu na Europa através dos mosteiros que eram construídos em terras de bárbaros convertidos, mas a religião dos celtas continuou no imaginário coletivo do camponês. Os trabalhos agrícolas eram regidos pelos astros, realizavam rituais de fertilidade e oferendas às forças da natureza. Havia mulheres com o saber de manipular o sobrenatural e ao repetirem o saber antigo na rotina do cotidiano, mantinham a herança que receberam do passado. Assim, eram tidas como perigosas para a nova religião.

Os livros de teologia moral registram que se peca por atos, palavras, pensamento e omissão. Falar com mulheres a sós era considerado pecado venial. Depois do homicídio, fornicar era o maior pecado. As relações carnais só eram válidas seguindo a lei e a boa ordem, isto é, dentro do casamento e só para ter filhos, pois não se devia gastar munição para se degradar. Mais grave ainda era que os vícios recaíam sobre os filhos, que nasciam com defeitos. O homem desonesto vive triste e lânguido, matar-se-á ou morrerá antes do tempo (Lavraga, 1866, p. 681).

Nesses manuais teológicos os prazeres sexuais são apontados como as causas principais das enfermidades de espasmo, convulsões, congestões e esgotamento de força. A terrível masturbação deixava os rapazes de físico seco, árido e dissipado, embrutecen- 
do-os com a perda das faculdades intelectuais. Nas moças provocava a perda da visão e debilitava o corpo. Os voluptuosos perdiam a memória e causavam danos ao coração. Mas para todos estes perigos diabólicos havia remédios eficazes: comer carne de porco, comer vegetais, não beber vinho, cerveja ou licor, cear pouco, tomar banho de rio ou na rua com o ar do campo, dormir em cama dura, evitando o calor de muitas cobertas, era conveniente deitar do lado direito, nunca de costas e muito menos na perigosa posição de boca para baixo. Para evitar toques durante a noite, deviase usar camisola com mangas compridas e fechadas (Lavraga, 1866, p. 684).

Era muito fácil atravessar a fronteira para o lado do Demônio.

O padre Sepp considerava os índios como crianças extremamente ingênuas e de tão escasso entendimento que os primeiros missionários achavam que eles não poderiam receber os sacramentos (Sepp, 1971, p. 215).

Essa mentalidade influiu na cultura brasileira. O tupi e o guarani, que chegaram a ser linguagem do campesino e caboclo, desapareceu, considerado como coisa bárbara. Hoje a população rural no Brasil não fala mais o idioma indígena, embora grande parte dos acidentes geográficos tenham nomes indígenas, como Itapuã, Jacuí, Taquari, Itacolomi e outros.

As reduções ou aldeamentos de índios cristãos pelos jesuítas, na chamada província jesuítica do Paraguai, não serviram apenas para separar os soldados de Cristo dos soldados do demônio. As reduções ou pueblos, com os missioneiros transformados em súditos do rei de Espanha, serviram para garantir a navegação dos espanhóis pelos rios Paraguai, Paraná e Uruguai, convertendo ou matando os índios que impediam a livre passagem.

Em várias cartas dos jesuítas encontra-se a referência de que os pueblos serviam de fronteira ao sistema colonial espanhol. A idéia de que as reduções formavam um espaço ou província à parte, está presente nas relações e cartas ânuas. No relatório de 1640 , ao narrar a situação da redução de Nuestra Señora de los Reyes de Yapeyu, o missionário informa que

"esta redução é a mais trabalhosa de todas, porque está mais afastada e por ser a gente dela mesclada de várias nações por ser a fronteira dos índios yarós e charruas" (Cortesão, 1969, p. 175).

As reduções jesuíticas constituíram-se num modelo de evangelização, mas não podemos esquecer que também serviram ao projeto colonial, tanto português como espanhol, para a conquista 
de povos tidos como bárbaros, permitindo a circulação por trilhas e rios, controlando politicamente as fronteiras coloniais entre portugueses e espanhóis.

Em nenhum momento os missionários tentaram a hegemonia das reduções em relação ao sistema colonial, trabalharam dentro da caridade cristã de auxiliar os pobres de espírito, como eram considerados os índios, mesmo quando os defendiam da escravidão. A evangelização nas reduções é um modelo de experiência mística na formação de uma nova cristandade, sem a preocupação de inserir o índio na sociedade dos brancos. Bastava salvar a alma.

O mundo do gentio representava a desordem, o reino do diabo, dos vícios e dos pecados. A ação dos missionários jesuítas, como soldados de Cristo, fazia parte de um novo espírito de organização do mundo, a serviço de Deus.

A confissão era uma forma de conversão do índio ao serviço de Deus e do Rei, era também um meio de obrigar os nativos a abandonarem a antropofagia, a poligamia, o sexo desregrado, a embriaguez, a preguiça e a feitiçaria, livrando suas mentes e corpos dos assaltos do diabo. Confessando-se e penitenciando-se, eles transpunham a fronteira entre o espaço de Deus e o do diabo, ingressando na cristandade, passando a ser índios civilizados.

Os brasileiros desbravaram o sertão, tido como domínio do diabo, com tropas de mulas, em busca de ouro, criando gado, capturando índios. Por fim, tiveram filhos com índias e negras. De tanto os missionários assustarem os brasileiros com o demônio, ele perdeu sua força, é tratado como o cão, o compadre, o capeta, o coisa ruim, que é enganado, ridicularizado e só mete medo em europeus. A fronteira da cristandade se enfraquece e o sincretismo religioso amplia seu espaço. No imaginário brasileiro o Diabo se transformou num pobre diabo, mesmo porque nada há a temer, pois Nossa Senhora da Imaculada Conceição é padroeira do Brasil e, no misticismo afro-brasileiro, Ogum é o senhor da demanda. Estamos salvos.

\section{Referências bibliográficas}

ANCHIETA, José de. Cartas: informações, fragmentos históricos e sermões. Belo Horizonte/São Paulo: Itatiaia/USP, 1988.

- De gestis Mendi de Saa. Rio de Janeiro: Arquivo Nacional, 1958.

CORTESÃtas inéditas. Rio de Janeiro: Fundação Getúlio Vargas, 1989.

1969.
CRTESA Jaime. Jesuitas e Bandeirantes no Tape. Rio de Janeiro: Biblioteca Nacional,

ELIADE, Mircea. O sagrado e o profano - a essência das religiões. Lisboa: Livros do Brasil, s. d.

Mito y realidad. Madrid: Guadarrama, 1973. 
FLORES, Moacyr. Colonialismo e missões jesuíticas. Porto Alegre: EST, 1996.

HOORNAERT, Eduardo. História geral da Igreja na América Latina. Petrópolis: Vozes, 1979.

KRAMER, Heinrich \& SPRENGER, James. O martelo das feiticeiras. Rio de Janeiro: Rosa dos Tempos, 1991.

LAVRAGA, Francisco. Prontuário de la teologia moral. Barcelona: Pablo Riega, 1866.

MONTOYA, Ruiz de. Conquista espiritual. Porto Alegre: Martins, 1985.

MORÁLES PADRÓN, Francisco. História de América. Madrid: Espasa-Calpe, 1962.

MURATORI, Ludovico Antônio. O cristianismo feliz nas missões jesuíticas. Santa Rosa: Instituto Educacional Dom Bosco, 1993.

NÓBREGA, Manoel da. Cartas do Brasil. Belo Horizonte/São Paulo: Itatiaia/USP, 1988.

REGIDOR, José Ramos. Teologia do sacramento da penitência. São Paulo: Paulinas, 1989.

SEPP, Antônio. Relación de viaje a las misiones jesuíticas (tomo I). Buenos Aires: Universitária, 1971.

VASCONCELOS, Simão de. Crônica da Companhia de Jesus. Petrópolis/Brasília: Vozes/MEC, 1977. 